\title{
THE CHEMICAL RESEARCH LABORATORY
}

\author{
REPORT FOR 1957
}

\begin{abstract}
HE report of the Director of the Chemical Research Laboratory which accompanies the report of the Chemistry Research Board under the title "Chemistry Research, 1957"* is the last which will cover the work of the laboratory under that title, which has now been changed to the National Chemical Laboratory, and the Board itself was being disbanded on September 30 and replaced by a Steering Committee. The new unit at Harwell, which is to co-operate with the Atomic Energy Authority, is studying possible applications of radioisotopes and began work there on October 1, 1957. To permit extension of the programme carried out for the Authority on the extraction of radioactive elements from minerals and ores the Authority is extending the Radiochemical Building and increasing the staff engaged on its behalf. The Authority is also contributing to the intensification of work on chelating and complexing resins. After a critical review during the year of the scheme of providing standard organic compounds, the Board agreed that the charges made for pure standard samples should fully cover the cost of the service, and to economize scientific effort recommended that the preparation of standard materials should be limited to those not available by purchase elsewhere. The Board's report also emphasizes the urgent need to expand work in the inorganic field.
\end{abstract}

The Director's report notes the increased effort given during the year to the work on the extraction, concentration and purification of elements from ores and low-grade materials, the preparation of ionexchange membranes and the synthesis of complexing resins. Among advances to which he directs particular attention are the construction of three experimental water-circulating systems to study the failure of tubes by corrosion, in water-circulating systems of modern engineering projects, and the development of an experimental technique to give reproducible results. The formation of an absorbed film and the subsequent growth of an oxide film have been followed by radiometric methods. A rapid method has been developed of concentrating the less plentiful constituents of rare-earth mixtures using a partial chromatographic technique, and further studies of zone-refining have shown that with tellurium, indium, tin and antimony the method is not effective in removing all the impurities as required by the electrical industry. The possibility of recovering germanium from ammoniacal liquor has also been examined. Advances are reported with resin-inpulp and solvent extraction processes for extracting and recovering uranium and thorium from ores, and an ion-exchange phosphorylated cellulose has been developed for recovering thorium from sulphate solutions of monazite as well as a field method, which can be used by relatively unskilled personnel, for determining as little as 0.001 p.p.m. of uranium in river water.

* Department of Scientiflc and Industrial Research. Chemistry Research 1957: The Report of the Chemistry Research Board with th Report of the Director of the Chemical Research Laboratory. Pp. iv +96. (London: H.M. Stationery Office, 1958.) 5s. net.
The work of the Organic Group has included a new study of the synthesis and application of certain organo-metallic compounds with special reference to the preparation of materials of high thermal stability, further work on the isomerization of ethylcyclopentane, the reactions of nascent carbon-14, the rearrangement of dipotassium salicylate and hydrazine poly. mers and the polymerization of aromatic isocyanates. Progress is reported in the purification and measurements work, including the construction of a highvoltage paper-electrophoresis apparatus and appar. atus for the direct measurement of latent heats of vaporization and specific heats of vapours. Encouraging progress is also reported in the preparation of new types of ion-selective membranes, and cationand anion-selective membranes based on polyvinyl chloride have shown very promising mechanical and electrochemical properties. In fractionating polymers it has been found that ${ }^{14} \mathrm{C}$-labelled polysarcosine dimethyl amides of molecular weights up to about 12,000 can be separated by paper chromatography using gradient elution, and studies on the random partial sulphonation of cross-linked polystyrene promise to throw light on the fundamental mechanism of ion-exchange.

A comprehensive collection of organisms used in the assay of amino-acids was built up in the National Collection of Industrial Bacteria during the year. Pilot-plant trials of the microbial production of sulphur from sulphate-enriched sewage sludge in progress at the London County Council's Northern Outfall Works at Beckton have confirmed earlier laboratory experiments in that the final sludge 'dewaters' more efficiently than sludge digested from methane. The great reduction in the volume of solids for disposal and consequent saving in transport costs may have an important influence on the economics of the process. Other work by the Microbiology Group has been concerned with the microbial formation of methane and with the bacterial oxidation of aromatic compounds, including benzenesulphonic acid and catechol, and the perfusion apparatus described in the 1956 report has been used to satisfy requests from industry for organisms capable of destroying such recalcitrant chemicals as methylated and unmethylated aryl sulphonates, thiocyanates and $\beta$-naphthol.

The Chemical Engineering Group is studying the rate of solution of gases in agitated liquids and has devised an optical device for measuring the interfacial area in gas-liquid dispersions. It has also obtained valuable data on the evaluation of mass transfer coefficients.

About 10 per cent of the time of senior staff is occupied with advisory work, and at the end of the year the total staff, including 58 scientific officers, 86 experimental officers, 34 assistants (scientific) and 2 works technical officers, numbered 239 compared with 223 at the end of 1956 . Appendixes list the staff in post on December 31, 1957, as well as the committees of the Board, patents publications during the year, standard samples of organic compounds and organisms deposited in the National Collection of Industrial Bacteria. 